\title{
HEPAMETA - PREVALENCE OF HEPATITIS B/C AND METABOLIC SYNDROME IN POPULATION LIVING IN SEPARATED AND SEGREGATED ROMA SETTLEMENTS: A METHODOLOGY FOR A CROSS- SECTIONAL POPULATION-BASED STUDY USING COMMUNITY-BASED APPROACH
}

\author{
Andrea Madarasová Gecková1, ${ }^{2}$, Peter Jarčuška ${ }^{3}$ Mária Mareková4, Daniel Pella ${ }^{3}$, Leonard Siegfried ${ }^{5}$, Pavol \\ Jarčuška ${ }^{6}$, Monika Halánová7; HepaMeta Team* \\ ${ }^{1}$ Health Psychology Unit, Department of Public Health, Faculty of Medicine, P. J. Šafárik University in Košice, Košice, Slovakia \\ 2Olomouc University Social Health Institute, Palacký University in Olomouc, Olomouc, Czech Republic \\ ${ }^{3} 1$ st Department of Internal Medicine, P. J. Šafárik University in Košice, Faculty of Medicine and L. Pasteur University Hospital, Košice, Slovakia \\ ${ }^{4}$ Department of Medical and Clinical Biochemistry and LABMED, Faculty of Medicine, P. J. Šafárik University in Košice, Košice, Slovakia \\ ${ }^{5}$ Department of Medical Microbiology, P. J. Šafárik University in Košice, Faculty of Medicine and L. Pasteur University Hospital, Košice, Slovakia \\ ${ }^{6}$ Department of Infectious Diseases, P. J. Šafárik University in Košice, Faculty of Medicine and L. Pasteur University Hospital, Košice, Slovakia \\ ${ }^{7}$ Department of Public Health, Faculty of Medicine, P. J. Šafárik University in Košice, Košice, Slovakia
}

\section{SUMMARY}

Background: Roma represent one of the largest and oldest minorities in Europe. Health of many of them, particularly those living in settlements, is heavily compromised by poor dwelling, low educational level, unemployment, and poverty rooted in generational poverty, segregation and discrimination. The cross-sectional population-based study using community based approach aimed to map the prevalence of viral hepatitis $\mathrm{B} / \mathrm{C}$ and metabolic syndrome in the population living in separated and segregated Roma settlements and to compare it with the occurrence of the same health indicators in the majority population, considering selected risk and protective factors of these health indicators.

Methods: The sample consisted of 452 Roma (mean age $=34.7 ; 35.2 \%$ men) and 403 non-Roma (mean age $=33.5 ; 45.9 \%$ men) respondents. Data were collected in 2011 via questionnaire, anthropometric measures and analysed blood and urine samples. A methodology used in the study as well as in the following scientific papers is described in the Methods section (i.e. study design, procedures, samples, methods including questionnaire, anthropometric measurements, physical measurements, blood and urine measurements).

Conclusions: There are regions of declining prosperity due to high unemployment, long-term problems with poverty and depleted resources. Populations living in these areas, i.e. in Central and Eastern Europe in Roma settlements, are at risk of poverty, social exclusion and other factors affecting health. Therefore, we should look for successful long-term strategies and tools (e.g. Roma mediators, terrain work) in order to improve the future prospects of these minorities.

Key words: Roma settlements, disadvantaged groups, health, health-related behaviour, socioeconomic indicators, living conditions

Address for correspondence: M. Halánová, Department of Public Health, Faculty of Medicine, P. J. Šafárik University in Košice, Tr. SNP 1, 04011 Košice, Slovakia. E-mail: monika.halanova@upjs.sk

\section{INTRODUCTION}

Roma (gypsies) are one of the largest and oldest minorities in Europe. Health of many of them, particularly those living in settlements, is heavily compromised by poor dwelling, low educational level, unemployment, and poverty rooted in generational poverty, segregation and discrimination (1-3). More than 400,000 Roma are estimated to live in Slovakia representing $7.5 \%$ of Slovak population (4). More than half of them live

\footnotetext{
*HepaMeta Team members are listed in Appendix
}

either in urban areas within or on the outskirts of towns or villages (36.7\%), or in separated or segregated Roma settlements (17\%) (4). It should be mentioned that estimated size of Roma population varies considerably based on the source, e.g. census, mapping of Roma settlements. Identifying and demarcating the population is problematic. Data on ethnicity is lacking in most routinely collected data (5), and the use of self-identification, identification according to language, identification by another person, or according to locality is problematic.

Roma are characterised by an extremely high degree of territorial segregation, poverty and perceived discrimination. Furthermore, the Roma population is characterised by a low 
educational level and high unemployment (1-2). Only a small proportion (39\%) of young Roma in Slovakia continue education after elementary school (2). The health of the majority of Roma is worse than that of the non-Roma population in Slovakia (1, 3). In addition, all available data indicate that the health of the majority of Roma is deteriorating at present, a fact particularly true for those living in large and isolated Roma settlements (1).

Worse health of Roma living in settlements in comparison to the majority population might be attributed to differences in living conditions, different access to goods and services, the extent of poverty - the major cause of these differences is not ethnicity but different socioeconomic characteristics; cultural differences resulting to differences in health literacy, health related behaviour (nutritional habits, use of psychoactive substances, physical activity, disease prevention) and consequently leading to gaps in health care; discrimination-related stress, social exclusion, material and financial deprivation, and lower socioeconomic position resulting in undesirable health consequences; the disadvantage conditions in early childhood which tends to cumulate in each subsequent critical life period and may result in widening differences in health resulting in a shorter life expectancy (6-10). From a public health point of view Roma living in settlements represent population at risk and hard-to-reach, and require a special attention.

The aim of the cross-sectional population-based study using community based approach was to map the prevalence of viral hepatitis $\mathrm{B} / \mathrm{C}$ and metabolic syndrome in the population living in separated and segregated Roma settlements and to compare it with the occurrence of the same health indicators in the majority population, considering selected risk and protective factors of these health indicators. A methodology used in this and other scientific papers presented in this issue is described in the following section.

\section{MATERIALS AND METHODS}

Data from the cross-sectional population-based HepaMeta study conducted in Slovakia in 2011 were used. This project aimed to map the prevalence of viral hepatitis B/C and metabolic syndrome in the population living in separated and segregated Roma settlements and to compare it with the occurrence of the same health indicators in the majority population, considering selected risk and protective factors of these health indicators.

The HepaMeta study was set up following the principles of community-based participatory research. Roma as target group were involved in the process of questionnaire development (designing and piloting) and data collection through active involvement of Roma community workers in all phases of the study.

The highest concentrations of Roma population in Slovakia can be found in the eastern part of the country (11). Therefore, the target population comprised residents of settlements in the Košice region aged 18-55 years, and the control group was the majority population in the same region and of the same age composition. We contacted 19 general practitioners (GPs) from a list of those operating in the catchment area with the target Roma population, and 12 agreed to take a part in the study (response rate of 63\%). For the majority population in the catchment area with no Roma population 7 general practitioners were randomly chosen from a list of general practitioners in the selected area; 5 agreed to take a part in the study (response rate of 71\%). Inclusion criteria for the respondents were as follows: no preventive medical check-up in past two years, no acute illness, age between 18 to 55 years, and availability during the week of data collection.

Roma in the selected settlements were recruited by local Roma community workers. From all Roma who were present in the settlements and received information about the study, 452 Roma chose to participate. Since the recruitment of Roma respondents was carried out under unpredictable conditions in Roma settlements, we were not able to compute the response rate.

A total of 710 people from the majority population were randomly chosen from a list of patients. These were contacted via phone and via mail by trained research assistants, who provided the information about the study and invited them to participate. A total of 403 participated in the study (response rate of 56.8\%). The recruitment of the Roma and non-Roma population is visualised in Fig. 1.

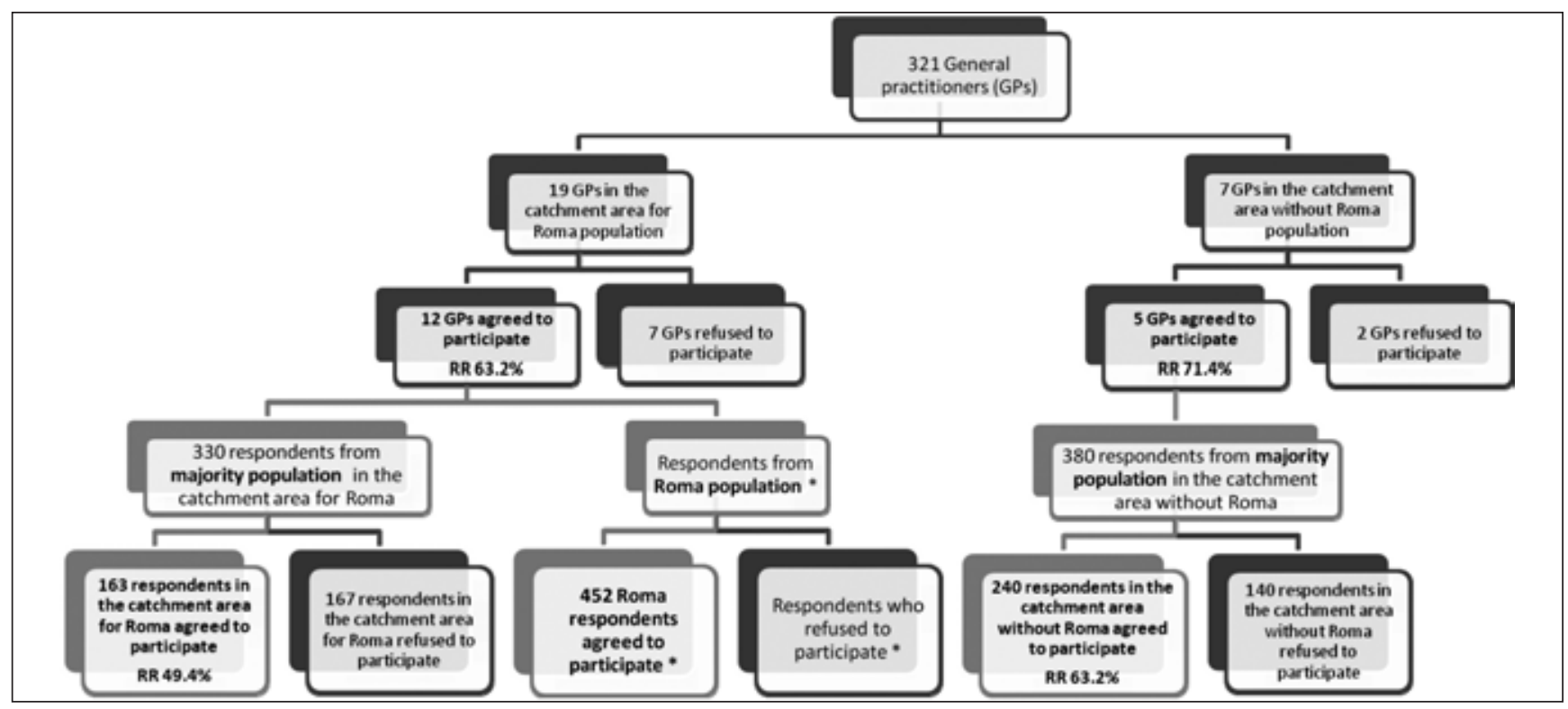

Fig. 1. Recruitment of the Roma and non-Roma population.

$\mathrm{RR}$ - response rate; * - missing data on response/non-response in Roma 
Trained medical personnel collected the blood and urine samples, performed anthropometric measurements and collect selected medical data (record on receiving blood transfusion, vaccination, selected cardiovascular, metabolic, pulmonary, and sexually transmitted disease and its drug treatment) in the offices of cooperating GPs. For the majority population trained assistants were present in the office to assist with questionnaires if needed. For Roma respondents, questionnaires were administered in community centres by community workers or trained assistants who provided help in case of limited literacy, which seemed to have the smallest impact on the data validity (12).

The study was approved by the Ethics Committee of the Faculty of Medicine at Šafárik University in Košice. Participation in the study was fully voluntary and anonymous. Detailed information about the study and its procedures was given to all respondents, and informed consent was obtained prior to the medical examination.

\section{QUESTIONNAIRE}

The questionnaire was developed by a group of experts made up of Roma health mediators and community workers, public health experts and academics. It gathered information about sociodemographic background, living conditions, health-related behaviour, health, and health care use.

\section{Socioeconomic Characteristics, Living Conditions}

Highest education was measured by asking respondents about their highest educational degree attained. Possible responses were: unfinished elementary/finished elementary/apprenticeship/ secondary/university.

Employment status: Respondents were asked if they are currently employed (except for community service) or unemployed, and what is the reason of current unemployment status.

Social benefits were investigated by asking respondents whether they received a social benefit last year. Possible responses were: yes/no.

Ability to pay bills was measured by asking respondents the question: "Did your household have a problem paying some of the following items?” They should mark each valid answer from the following list: rent/collection order (e.g. payments for electricity, water, gas, TV)/current expenditure and purchase (e.g. food, clothing, travel costs)/purchase ante, credit ante, other loans/health care costs (medicaments, travel costs).

Standard household equipment was examined by questioning respondents: “Is there in your house a...?” Possible answers were: functioning sewage system/water supply/functional flushing toilet/functional bathroom or shower/electricity. Respondents should mark each valid alternative.

Source of heating: Respondents were asked what is the main type of heating system in their household (central heating system, e.g. radiator/iron oven/brick oven - tile stove/oven made from other materials/fireplace/open fireplace/electric heater). The second question: "Which of the following items do you use for heating at your home?” had these possible responses: natural wood (trees), black or brown coal/other material (garbage, other items like old furniture parts etc., oil, gasoline or petrol, others).
Household overcrowding was examined through the question: "Does every family (married couple) living in your habitation has its own room?" with possible responses of yes/no; and by the question: "How many families (married couples) live in the household" (number of families), and how many adults and minors live in the household?

\section{Health-related Behaviour}

With regard to eating habits, respondents were asked if they breakfast at least four times per week (yes/no), and about recent ("yesterday and today") consumption of the following foodstuffs: fruit - apple, banana, orange, or other raw fruit; vegetables tomatoes, green pepper, lettuce, or other raw vegetables; dairy products - milk, yoghurt, cheese, or other dairy products; meat products - salami, sausage, ham, or other meat products; meat - schnitzel, roast chicken, steak, or other meat; dishes from flour - pasta, noodles, dumplings, pancakes, or other farinaceous foods; soft drinks - cola, lemonade or other soft drinks. Possible responses were yes/no. Days after Sundays as well as days when welfare benefits are received were excluded from the data collection schedule.

Physical activity was measured by asking respondents two questions. The variety of physical activities was measured by asking respondents what physical activity, if any, they had performed during the last week. They could select one or more possibilities from the following list: physical activity at work; physical work around the house or home; brisk walking; dancing; sport; no physical activity (marking each valid alternative).

Respondents were also asked how often in a week they performed physical activity lasting at least 30 minutes, during which they became breathless or sweaty. Possible responses were: every day; 4-6 times a week; 2-3 times a week; once a week; 2-3 times a month; a few times a year or less.

Smoking: Respondents were asked if they currently smoke cigarettes, cigars, pipes, or tobacco, and could answer by selecting from the following options: I do not smoke; I smoke sometimes but not daily; I smoke daily; I smoked in the past, but I quit completely. If they did smoke, they were then asked whether they had smoked during the day before: 6 or more cigarettes; less than 6 cigarettes; or did not smoke.

Alcohol consumption was measured by asking about the consumption of 6 or more doses of alcohol on one occasion (1 dose $=0.5$ litres of beer, 0.2 litres of wine or 0.05 litres of spirits). Possible responses were: never; less than once a month; once a month; once a week; daily or almost daily.

Similarly, respondents were asked about the amount of alcohol consumed the day before, and they could respond by selecting from the following options: I drank 6 or more doses of alcohol; I drank 1-5 doses of alcohol; I did not drink.

Drug use was assessed separately for intravenous drugs (yes or no question) and toluene, marihuana or any drugs in the form of tablets or powder (multiple choice questions with possible answers: never; tried once or twice; regularly, but less than once a month; multiple times in a month; once a week; multiple times a week; daily.

Sexual behaviour was explored by six questions. Respondents were asked if they ever had sex (yes/no); in what age (less/ more than 15 years old); how many sexual partners they had 
(one/2-4/5-9/10 to 24/more than 25); whether they used condom in the past year (always, almost always, rarely or never), and what was the reason (prevention of unwanted pregnancy/prevention of sexually transmitted diseases); and whether they ever had paid sex (yes/no). Respondents were asked if they have a permanent skin tattoo and if they have piercing or earring with possible answers: no; yes, done in the GP office, salon or official tattoo parlour; yes, done privately.

Responders were asked if they were ever in prison with possible responses: never; less than one year; more than one year.

\section{Health Status}

Self-rated health was measured by asking respondents the question: "Would you say your health is: Excellent/Good/Fair/ Poor?” (13).

Health complaints: Respondents were asked whether they suffered any of the listed health symptoms in the past month: headache, stomachache, cold, flu, muscle pain, back pain, anxiety, cough, tiredness, sleepiness, stress, obstipation, diarrhoea, allergies, other.

Life satisfaction was measured with the Satisfaction with Life Scale developed by Diener et al. (14). It is a 5-item measure (examples: the conditions of my life are excellent; I am satisfied with my life) with answers (values) ranging from strongly disagree - 1 to strongly agree -7 .

Social support was measured using the Perceived Social Support Scale (15), which is a 12-item self-reported questionnaire assessing perceived social support in three dimensions (from the family, friends and significant others). A seven-point Likerttype format was used ranging from totally disagree -1 to totally agree -7 . The score for each of the 4 -item subscales ranges from 4 to 28, with a higher score indicating a higher level of perceived social support.

Medical services use: Respondents were asked whether they went through preventive check-ups in general practitioner's office during the last two years (yes/no); and in case of women, whether they underwent preventive check-up in their gynaecologist office (yes/no), and number of deliveries.

Medical drug use was determined by asking if respondents use any of the listed drugs: lipid lowering medication, other painkillers, anticough medication, anxiolytics, vitamins, nutritional supplements, contraceptive medication. Respondents should mark each valid alternative.

Barriers in accessing health services were measured by asking respondents how difficult is it for them to access health services (it is not difficult/ it is manageable, but not easy/ it is not manageable without assistance); who is able to help them when they need to arrange medical services (family/friends, neighbours/ community workers/mayor/priest/nobody/other), and what are the main reasons for the difficulties in seeking and providing the necessary health services. Possible responses were: "I do not have enough money for medication and transportation to a doctor." "I do not know where to seek health services/I cannot find it in the city/village." "I have very bad transport connection to health services." "I do not trust health care professionals." "I once had a bad experience when visiting a doctor/I fear the examination.” "I have difficulties with providing babysitting for my children when I or one of my children need to see a doctor." "I prefer to treat myself at home using my own curative methods” (marking each valid alternative).

\section{ANTHROPOMETRIC MEASUREMENTS}

Height and weight were measured using a scale. Waist and hip circumferences were measured using plastic tapes mid-way between the lowest rib and the iliac crest (the subjects standing after gently exhaling), and at the greater trochanters, respectively. Waist to hip circumference ratio (WHR) was calculated by dividing the abdominal circumference by the hip circumference. Body mass index (BMI) was calculated by dividing body weight (kilograms) by height squared (square meters). BMI is a simple index that is commonly used to classify underweight, overweight and obesity in adults (Table 1 ). BMI $\geq 30$ was used as the criterion of obesity (16-17).

\section{PHYSICAL MEASUREMENTS}

Blood pressure was taken using the Omron M3 digital automatic blood pressure monitor after 5 minutes of rest in a sitting position. The mean value of three blood pressure measurements was used in the analysis. The limit for normal systolic blood pressure was $<130 \mathrm{mmHg}$ or normal diastolic blood pressure $<85 \mathrm{mmHg}$ (18).

\section{BLOOD SAMPLE MEASUREMENTS}

Collection of venous blood was carried out under standard conditions, after overnight fasting, in a seated position, from a pe-

Table 1. Classification of overweight and obesity by BMI, waist circumference and associated disease risk

\begin{tabular}{|c|c|c|c|c|}
\hline & & & Disease risk relative to $n$ & and waist circumference \\
\hline & $\operatorname{BMl}\left(\mathrm{kg} / \mathrm{m}^{2}\right)$ & Obesity class & $\begin{array}{c}\text { Men } \leq 102 \mathrm{~cm} \\
\text { Women } \leq 88 \mathrm{~cm}\end{array}$ & $\begin{array}{c}\text { Men>102 cm } \\
\text { Women }>88 \mathrm{~cm}\end{array}$ \\
\hline Underweight & $<18.5$ & & & \\
\hline Normal & $18.5-24.9$ & & & \\
\hline Overweight & $25.0-29.9$ & & Increased & High \\
\hline \multirow{2}{*}{ Obesity } & $30.0-34.9$ & I & High & Very high \\
\hline & $35.0-39.9$ & $\|$ & Very high & Very high \\
\hline Extreme obesity & $\geq 40.0$ & III & Extremely high & Extremely high \\
\hline
\end{tabular}


ripheral vein in the antecubital fossa. Samples were collected and modified (centrifuged, frozen) at biochemical laboratory of the Department of Medical and Clinical Biochemistry and LABMED, Faculty of Medicine, P. J. Šafárik University. The separated serum samples were transported in accordance with standard operating procedures for sampling and transport of biological material to the LABMED laboratory holding a certificate of quality management as well as the necessary professional certification for the individual examinations, in line with international standards. Clinical biochemistry tests for determination substrates: glucose, cysteine $\mathrm{C}$ - cysC, creatinine, urea, uric acid, bilirubin, minerals (Fe, $\mathrm{Ca}$ and unbound iron binding capacity - UIBC), proteins (total proteins, albumin - ALB, ferritin, transferrin and hs-CRP as risk factor), enzymes ( $\alpha$-amylase, alanine-aminotransferase-ALT, aspartate-aminotransferase - AST, gamma-glutamyl transferase - GGT or GMT, alkaline phosphatase - ALP) and lipid parameters (triacylglycerols - TAG or TG, total cholesterol - TC, HDL cholesterol - HDL-C, LDL cholesterol - LDL-C, apolipoprotein A - apoA, apolipoprotein B100 - apoB100). All biochemical parameters were determined by routine biochemical methods on analyser ADVIA 2400 or 1650 . Ferritin was measured by chemiluminescent immunoassay (CLIA) on analyser ADVIA Centaur (Siemens). Reference ranges for clinical-biochemical parameters used in laboratory (LABMED, a.s.) were mostly recommended by producers of diagnostic kit.

The blood samples were serologically tested for hepatitis B and hepatitis C (HBsAg, anti-HBc IgG antibodies, anti-HCV antibodies) and HBV DNA. HBV DNA was sampled in HBsAgpositive participants only. HBsAg, anti-HBc IgG and anti-HCV testing were performed by Enzygnost (Siemens, Germany); HBV DNA was measured by HBV Cobas Taqman Ampli Prep/Cobas v 2.0 (Roche, Switzerland), with a detection limit of $20 \mathrm{IU} / \mathrm{ml}$ and an upper limit of 170,000,000 IU/ml. Patients were considered to have active $\mathrm{HBV}$ infection if they were HBsAg positive, and those with anti-HBc IgG or antiHBsAg positivity were considered to have had encountered HBV in the past or were vaccinated.

Bioactive mediators of tumour necrosis factor-alpha (TNF- $\alpha$, DRG International, Inc. USA), adiponectin (Adipogen International, Denmark), interleukin 6 (IL-6, DRG International, Inc. USA) and leptin (BioVendor, Czech Republic) were determined by ELISA methods according to the manufacturer's instructions.

The International Diabetes Federation standard criteria were used for the determination of metabolic syndrome (MS) (18). Patients were considered to have MS when central obesity (waist circumference $\geq 94 \mathrm{~cm}$ for males and $\geq 80 \mathrm{~cm}$ for females or BMI $>30$ $\mathrm{kg} / \mathrm{m}^{2}$ ) plus any two of the four following factors were present: raised TG $\geq 1.7 \mathrm{mmol} / \mathrm{l}(150 \mathrm{mg} / \mathrm{dl})$ or specific treatment for this lipid abnormality; reduced HDL-C $<1.03 \mathrm{mmol} / \mathrm{l}$ (40 mg/dl) in males and $<1.29 \mathrm{mmol} / \mathrm{l}(50 \mathrm{mg} / \mathrm{dl})$ in females or specific treatment for these lipid abnormalities; raised systolic blood pressure $\geq 130 \mathrm{mmHg}$ or diastolic blood pressure $\geq 85 \mathrm{mmHg}$ or treatment of previously diagnosed hypertension; raised fasting plasma glucose $\geq 5.6 \mathrm{mmol} / \mathrm{l}(100 \mathrm{mg} / \mathrm{dl})$ or previously diagnosed type 2 diabetes.

Diagnostic criteria used for further cardiovascular diseases risk factors in the HepaMeta study were: $\mathrm{TC} \geq 5.0 \mathrm{mmol} / \mathrm{l}$, LDL$\mathrm{C} \geq 3.0 \mathrm{mmol} / 1$, LDL-C/HDL-C $\geq 3.3$ (19-21). GGT levels were considered to be elevated if they were higher than $0.98 \mu \mathrm{kat} / \mathrm{l}$ in men and $0.66 \mu \mathrm{kat} / \mathrm{l}$ in women.

\section{URINE SAMPLE MEASUREMENTS}

First morning void was collected, cooled and semi-quantitatively analysed up to 4 hours using an 10 parameters urine strip test DekaPhan (LachemaLeuco, Czech Republic). Participants were given a morning appointment and asked to fast for at least 8 hours before the urine collection. Compliance with these requests was confirmed upon arrival. Participants were given a plastic container and detailed instruction about the first morning urine sample collection. The limit for proteinuria analysis was $0.15 \mathrm{~g} / \mathrm{l}$, and according to the manufacturer, a sample could be categorised as negative (<0.15 g/l), “+” (0.3 g/l), “++” $(1 \mathrm{~g} / \mathrm{l})$ or “+++” (5 g/l). The limit for hematuria analysis was 5 Ery/ $\mu$ l, and according to the manufacturer the sample could be categorised as negative $(<5$

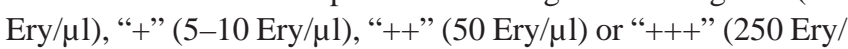
$\mu \mathrm{l})$. Because there were too many false positive samples (resulting in an unrealistically high 52\% prevalence of nephropathy), only those marked as “++" or “+++" were considered to be positive. Diagnostic criteria used for further urine evaluation categorised as negative were: glucose $<1.4 \mathrm{mmol} / \mathrm{l}$, ketone bodies $<0.19$ $\mathrm{mmol} / \mathrm{l}$ (criteria defined by the manufacturer LachemaLeuco, CZ).

The Glomerular filtration rate (GFR) was calculated using the MDRD equation based on serum creatinine from a morning fasting serum sample (22). Because of cross-sectional nature of the study we did not use the term CKD, as it is appropriate only if the duration of kidney disease lasts 3 or more months. Instead, the term nephropathy was used and was defined as follows: a known history of any kidney disease; or presence of proteinuria or hematuria; or GFR $<60 \mathrm{ml} / \mathrm{min}$.

The occurrence of Chlamydia trachomatis in urine samples was detected by direct proof of the pathogen by polymerase chain reaction (PCR) using the commercial DNA-sorb-AM nucleic acid extraction kit and the AmpliSens ${ }^{\circledR}$ Chlamydia trachomatis-EPh PCR kit (the Federal Budget Institution of Science, Moscow, Russia). Extraction and purification of DNA as well as PCR analysis were performed according to the manufacturer's instructions.

\section{CONCLUSION}

There are regions of declining prosperity due to high unemployment, long-term problems with poverty and depleted resources. Populations living in these areas, i.e. in Central and Eastern Europe the populations living mainly in Roma settlements, are at risk of poverty, social exclusion and other factors affecting health. Therefore, we should look for successful long-term strategies and tools (e.g. Roma mediators, terrain work) in order to improve the future prospects of these minorities.

\section{Acknowledgement}

This research was partially supported by the Research and Development Support Agency, Contract No. APVV-00-032-11; the Agency of the Slovak Ministry of Education for the Structural Funds of EU, project CEMIO-ITMS: 26220120058 (30\%) and CEEPM-ITMS: 26220120067 (40\%). This paper was also partially funded within the framework of the project "Social determinants of health in socially and physically disadvantaged and other groups of population” (CZ.1.07/2.3.00/20.0063) and by Roche Slovensko, s. r. o. Research was also funded within the framework of the VEGA project, grant 1/1072/12; and a grant from Visegrad fund. 


\section{Conflict of Interests}

None declared

\section{APPENDIX}

HepaMeta Team: Peter Jarčuška, Andrea Madarasová Gecková, Mária Mareková, Daniel Pella, Leonard Siegfried, Pavol Jarčuška, Lýdia Pastvová, Ján Fedačko, Jana Kollárová, Peter Kolarčik, Daniela Bobáková, Zuzana Veselská, Ingrid Babinská, Sylvia Dražilová, Jaroslav Rosenberger, Ivan Schréter, Pavol Kristian, Eduard Veselíny, Martin Janičko, Ladislav Virág, Anna Birková, Marta Kmet’ová, Monika Halánová, Darina Petrášová, Katarína Cáriková, Viera Lovayová, Lucia Merkovská, Lucia Jedličková, Ivana Valková

\section{REFERENCES}

1. Vašečka M, Džambazovič R. The socio-economic situation of the Roma in Slovakia as potential migrants and asylum applicants in EU countries. In: The socio-economic situation of potential asylum applicants from the Slovak Republic. Bratislava: International Organization for Migration; 2000. p. 17-62. (In Slovak.)

2. European Union Agency for Fundamental Rights. European Union minorities and discrimination survey. Main results report. Vienna: European Union Agency for Fundamental Rights; 2009.

3. Ginter E, Krajcovicova-Kudlackova M, Kacala O, Kovacic V, Valachovicova M. Health status of Romanies (Gypsies) in the Slovak Republic and in the neighbouring countries. Bratisl Lek Listy. 2001;102(10):479-84.

4. Ministry of the Interior of the Slovak Republic. An atlas of Roma communities [Internet]. Bratislava: Ministry of the Interior of the Slovak Republic; 2013 [cited 2013 Nov 17]. Available from: http://www.minv. sk/?atlas_2013. (In Slovak.)

5. Kósa Z, Széles G, Kardos L, Kósa K, Németh R, Országh S, et al. A comparative health survey of the inhabitants of Roma settlements in Hungary. Am J Public Health. 2007 May;97(5):853-9.

6. Peters J, Parry GD, Van Cleemput P, Moore J, Cooper CL, Walters SJ. Health and use of health services: a comparison between Gypsies and Travellers and other ethnic groups. Ethn Health. 2009 Aug;14(4):359-77.

7. Rosicova K, Madarasova Geckova A, van Dijk JP, Kollarova J, Rosic M, Groothoff JW. Regional socioeconomic indicators and ethnicity as predictors of regional infant mortality rate in Slovakia. Int J Public Health. 2011 Oct;56(5):523-31.

8. Bastos JL, Celeste RK, Faerstein E, Barros AJ. Racial discrimination and health: a systematic review of scales with a focus on their psychometric properties. Soc Sci Med. 2010 Apr;70(7):1091-9.

9. Dressler WW, Oths KS, Gravlee CC. Race and ethnicity in public health research: models to explain health disparities. Annu Rev Anthropol. 2005; 34:231-52.
10. Wilkinson R, Marmot M, editors. Social determinants of health: the solid facts. Copenhagen: WHO Regional Office for Europe; 1998.

11. Slušná L. Slovakia: healthy communities. In: Koller T, editor. Poverty and social exclusion in the WHO European Region: health systems respond. Copenhagen: WHO Regional Office for Europe; 2010. p. 167-77.

12. Tourangeau R, Smith TW. Asking sensitive questions: the impact of data collection mode, question format, and question context. Public Opin Q. 1996;60(2):275-304.

13. Idler EL, Benyamini Y. Self-rated health and mortality: a review of twentyseven community studies. J Health Soc Behav. 1997 Mar;38(1):21-37.

14. Diener E, Emmons RA, Larsen RJ, Griffin S. The Satisfaction With Life Scale. J Pers Assess. 1985 Feb;49(1):71-5.

15. Blumenthal JA, Burg MM, Barefoot J, Williams RB, Haney T, Zimet G Social support, type A behavior, and coronary artery disease. Psychosom Med. 1987 Jul-Aug;49(4):331-40.

16. Clinical guidelines on the identification, evaluation, and treatment of overweight and obesity in adults - the evidence report. National Institutes of Health. Obes Res. 1998 Sep;6 Suppl 2:51S-209S.

17. Catapano AL, Reiner Z, De Backer G, Graham I, Taskinen MR, Wiklund O, et al.; European Society of Cardiology (ESC); European Atherosclerosis Society (EAS). ESC/EAS Guidelines for the management of dyslipidaemias The Task Force for the management of dyslipidaemias of the European Society of Cardiology (ESC) and the European Atherosclerosis Society (EAS). Atherosclerosis. 2011 Jul;217(1):3-46.

18. Alberti KG, Zimmet P, Shaw J. Metabolic syndrome - a new world-wide definition. A Consensus Statement from the International Diabetes Federation. Diabet Med. 2006 May;23(5):469-80.

19. Graham I, Atar D, Borch-Johnsen K, Boysen G, Burell G, Cifkova R, et al.; European Society of Cardiology (ESC) Committee for Practice Guidelines (CPG). European guidelines on cardiovascular disease prevention in clinical practice: executive summary: Fourth Joint Task Force of the European Society of Cardiology and Other Societies on Cardiovascular Disease Prevention in Clinical Practice (Constituted by representatives of nine societies and by invited experts). Eur Heart J. 2007 Oct;28(19):2375414.

20. Task Force for the management of dyslipidaemias of the European Society of Cardiology (ESC) and the European Atherosclerosis Society (EAS), Catapano AL, Reiner Z, De Backer G, Graham I, Taskinen MR, Wiklund O, et al.; ESC Committee for Practice Guidelines 2008-2010 and 2010-2012 Committees. ESC/EAS Guidelines for the management of dyslipidaemias: the Task Force for the management of dyslipidaemias of the European Society of Cardiology (ESC) and the European Atherosclerosis Society (EAS). Atherosclerosis. 2011 Jul;217 Suppl 1:S1-44.

21. Packard CJ, Ford I, Robertson M, Shepherd J, Blauw GJ, Murphy MB, et al.; PROSPER Study Group. Plasma lipoproteins and apolipoproteins as predictors of cardiovascular risk and treatment benefit in the PROspective Study of Pravastatin in the Elderly at Risk (PROSPER). Circulation. 2005 Nov 15;112(20):3058-65.

22. Menon V, Kopple JD, Wang X, Beck GJ, Collins AJ, Kusek JW, et al. Effect of a very low-protein diet on outcomes: long-term follow-up of the Modification of Diet in Renal Disease (MDRD) Study. Am J Kidney Dis. 2009 Feb;53(2):208-17. 